\title{
A 10-year-old child presenting with syndromic paucity of bile ducts (Alagille syndrome): a case report
}

\author{
Girish Kumar Pati ${ }^{1}$, Ayaskanta Singh², Preetam Nath', Jimmy Narayan', Pradeep Kumar Padhi', \\ Prasanta Kumar Parida ${ }^{1}$, Kaumudee Pattnaik ${ }^{3}$, Chittaranjan Panda ${ }^{1}$ and Shivaram Prasad Singh ${ }^{1 *}$
}

\begin{abstract}
Background: Alagille syndrome, a rare genetic disorder with autosomal dominant transmission, manifests with five major features: paucity of interlobular bile ducts, characteristic facies, posterior embryotoxon, vertebral defects, and peripheral pulmonary stenosis. Globally, only 500 cases have so far been reported, with only five cases reported in the Indian subcontinent. Rarely, Alagille syndrome also presents with skin manifestations and early-onset chronic liver disease, which was found in our case. We believe that we report what could be the first case of Alagille syndrome presenting with café au lait spots, as no such published case report could be found in the literature.

Case presentation: We report an unusual case of childhood cholestatic jaundice with neonatal onset of jaundice. A 10-year-old boy from the Indian subcontinent presented with obstructive jaundice from early infancy. He also had recurrent fractures of his upper limb bones, intermittent bleeding from his nose, productive cough, decreased night vision, hyperpigmented spots over his skin, and progressive enlargement of his abdomen. Histological examination of a liver biopsy specimen revealed a paucity of bile ducts and changes suggestive of chronic liver disease. Our patient was diagnosed with Alagille syndrome and managed conservatively but died 1 year after the final diagnosis.

Conclusions: This particular syndromic form of paucity of bile duct disorder has been rarely reported in the Indian literature so far. Our case is notable because the child had café au lait spots and very early onset of chronic liver disease, which is quite rare in Alagille syndrome. We believe this to be the first case report on Alagille syndrome manifesting with café au lait syndrome and such early onset of chronic liver disease.
\end{abstract}

Keywords: Alagille syndrome, Bile duct paucity, Butterfly vertebra, Café au lait spots, Posterior embryotoxon

\section{Background}

Alagille syndrome (AGS) was first described by David Alagille in 1975 as an autosomal dominant disease affecting multiple systems including the liver, heart, eyes, skeleton, and face [1-3]. It is characterized by a paucity of intrahepatic bile ducts with cholestasis and phenotypic manifestations. AGS is most commonly caused by mutations or deletions of the gene encoding Jagged 1 (JAG1), a ligand involved in the Notch signaling pathway [4]. We describe the case of a 10-year-old boy who

\footnotetext{
*Correspondence: scb_gastro_dept@hotmail.com

'Department of Gastroenterology, S.C.B. Medical College, Cuttack, Odisha, India

Full list of author information is available at the end of the article
}

presented with obstructive jaundice and other symptoms related to cholestasis from early infancy. Globally, only 500 cases [1] of AGS have been reported so far, with only five cases in the Indian subcontinent [5]. Rarely, AGS presents with skin manifestations and early-onset chronic liver disease (CLD), which was found in our case and is therefore worth reporting.

\section{Case presentation}

A 10-year-old boy from the Indian subcontinent presented with persistent jaundice, intermittent itching, and the passage of clay-colored stool from 10 days after birth. His parents noticed a slowly growing lump over the upper part of his abdomen of 7 years' duration. He 
also had a 6-year history of intermittent productive cough associated with sneezing, soreness of throat, rhinorrhea, and occasional fever. Episodes of productive cough usually occurred at intervals of 5-6 months (mostly during the winter months and rainy seasons), lasted for 3-5 days, and improved following treatment with expectorant and anti-allergic cold syrup. For the last 4 years he had experienced intermittent bleeding from his nose and the occasional appearance of posttraumatic violaceous-red patches at the site of trauma, as well recurrent post-traumatic fractures of his upper limbs following mild trauma. For the last 3 years, he had difficulty with night vision.

Our patient had no prior history of altered sensorium, blood vomiting, or passage of black stool. He was born 2 weeks after the expected date of delivery, had low birth weight $(2.1 \mathrm{~kg}$ ), delayed cry (cried after 5 minutes of birth), delayed mile stone development, and poor weight gain since early infancy. There was no family history of a similar type of illness, liver disorder, or consanguineous marriage: his parents, and his grandparents, were not related. He had no family or personal history of tuberculosis or, asthma. He had two elder asymptomatic healthy siblings.

His height was $113 \mathrm{~cm}$ (z-score <-3), weight $13 \mathrm{~kg}$ (z-score < -3), body mass index $10.23 \mathrm{~kg} / \mathrm{m}^{2}$, and midarm circumference $9 \mathrm{~cm}$. He had mild pallor, icterus, clubbing, multiple hyperpigmented spots (café au lait spot), and scratch marks over his skin. There was no pedal edema, purpura, palmer erythema, spider nevi, gynecomastia, or testicular atrophy. Our patient had peculiar facial features in the form of a triangular face with broad forehead, deeply set eyes, hypertelorism, prominent ears, small pointed chin, and saddle nose with a bulbous tip. The skin manifestation is shown in Fig. 1, which illustrates the presence of multiple hyperpigmented spots resembling café au lait spots.

Examination of his abdomen revealed enlargement of the left lobe of his liver. His liver was firm in consistency with an irregular margin and slightly nodular surface. His liver span was $9 \mathrm{~cm}$ along the right mid-clavicular line and his spleen was palpable $3 \mathrm{~cm}$ below the left costal margin and firm in consistency. An eye examination demonstrated posterior embryotoxon, iris strands, increased intraocular pressure (Fig. 2). Findings from respiratory and neurological examinations were normal.

The biochemical parameters of the patient along with corresponding reference ranges for the laboratory are described in Table 1. He tested negative for hepatitis-B surface antigen and anti-hepatitis $C$ virus antibodies. An $\mathrm{X}$-ray of his wrist showed gross osteopenia, and an Xray of his chest revealed cardiomegaly. Two-dimensional echocardiography showed pulmonary hypertension and tricuspid regurgitation. On gastroduodenoscopy there

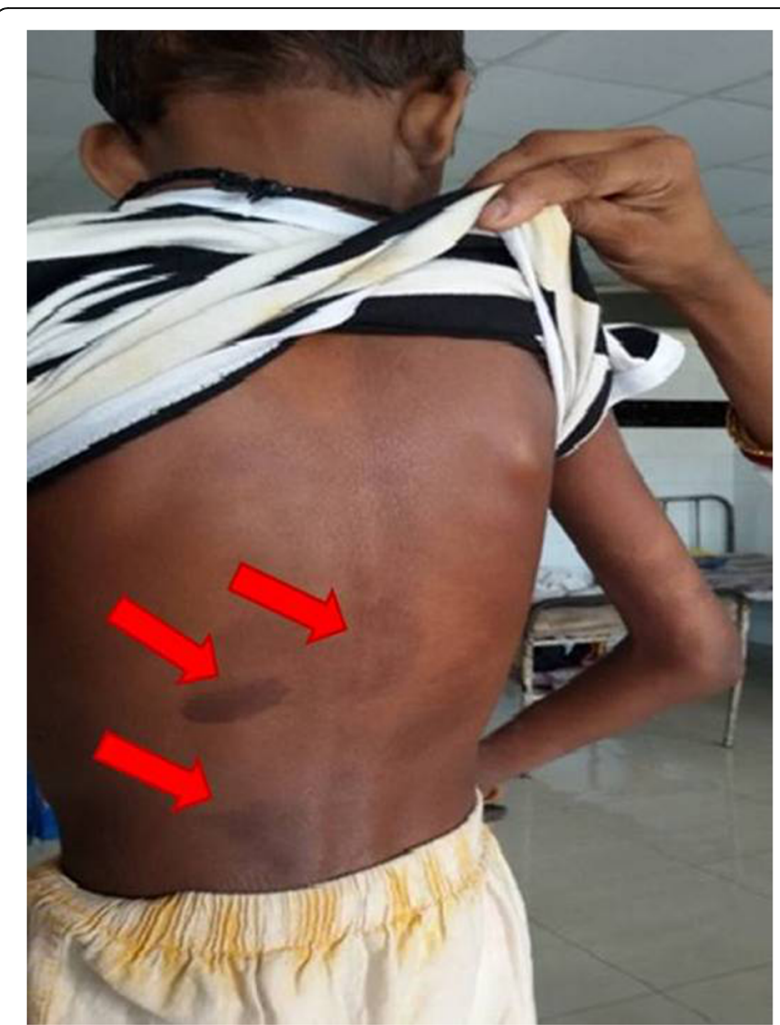

Fig. 1 Skin manifestations of the patient. Red arrows indicate hyperpigmented patches

were no esophageal or gastric varices. An ultrasonographic study of his abdomen reported a shrunken right lobe with coarse hepatic parenchyma, an enlarged left lobe, mild splenomegaly, and poorly visualized hepatic and portal veins. Liver biopsy tissue stained with hematoxylin and eosin showed 10 portal tracts with a conspicuous absence of interlobular bile ducts adjacent to the hepatocytes, a portal area with mild inflammation,

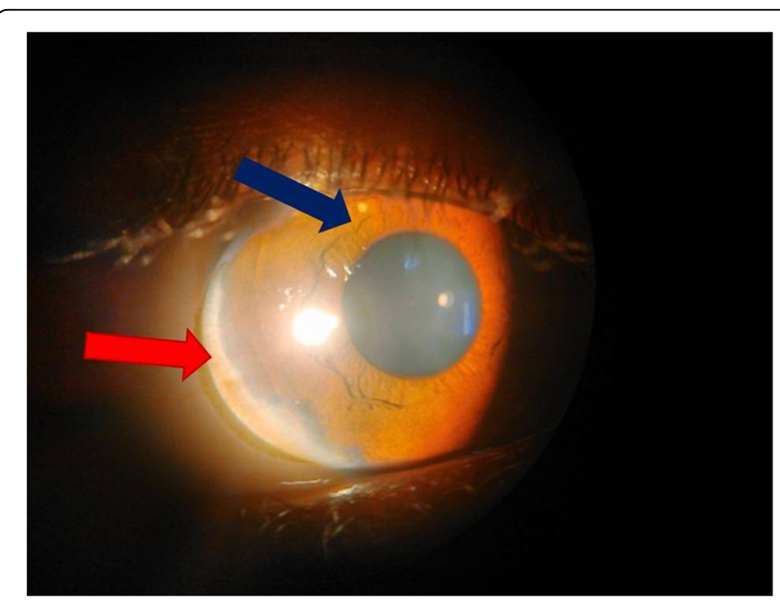

Fig. 2 Ophthalmological findings of the patient. Blue arrow indicates an iris strand; red arrow indicates posterior embryotoxon 
Table 1 The laboratory parameters of the patient along with corresponding reference ranges

\begin{tabular}{llll}
\hline Parameters & $\begin{array}{l}\text { Values in the } \\
\text { patient }\end{array}$ & $\begin{array}{l}\text { Normal reference } \\
\text { range }\end{array}$ & Inference \\
\hline Hemoglobin & $10.7 \mathrm{~g} / \mathrm{dL}$ & $14-16 \mathrm{~g} / \mathrm{dL}$ & Decreased \\
TLC & $8000 / \mathrm{mm}^{3}$ & $4000-11000 / \mathrm{mm}^{3}$ & Normal \\
TPC & $1.3 \mathrm{lakhs} / \mathrm{mm}^{3}$ & $1.5-4$ lakhs $/ \mathrm{mm}^{3}$ & Decreased \\
INR (PT) & 1.3 & $<1.2$ & Increased \\
Serum urea & $18 \mathrm{mg} / \mathrm{dL}$ & $15-45 \mathrm{mg} / \mathrm{dL}$ & Normal \\
Serum creatinine & $0.7 \mathrm{mg} / \mathrm{dL}$ & $0.5-1.5 \mathrm{mg} / \mathrm{dL}$ & Normal \\
Serum total bilirubin & $4.1 \mathrm{mg} / \mathrm{dL}$ & $0.1-1.2 \mathrm{mg} / \mathrm{dL}$ & Increased \\
Serum direct bilirubin & $3.4 \mathrm{mg} / \mathrm{dL}$ & $0.1-0.3 \mathrm{mg} / \mathrm{dL}$ & Increased \\
Serum AST & $292 \mathrm{IU} / \mathrm{L}$ & $10-40 \mathrm{IU} / \mathrm{L}$ & Increased \\
Serum ALT & $121 \mathrm{IU} / \mathrm{L}$ & $10-50 \mathrm{IU} / \mathrm{L}$ & Increased \\
Serum ALP & $978 \mathrm{IU} / \mathrm{L}$ & $250-750 \mathrm{IU} / \mathrm{L}$ & Increased \\
Serum GGT & $24 \mathrm{IU} / \mathrm{L}$ & $0-30 \mathrm{IU} / \mathrm{L}$ & Normal \\
Serum protein & $5.8 \mathrm{~g} / \mathrm{dL}$ & $5.5-7.5 \mathrm{~g} / \mathrm{dL}$ & Normal \\
Serum albumin & $2.4 \mathrm{~g} / \mathrm{dL}$ & $3.5-5.5 \mathrm{~g} / \mathrm{dL}$ & Decreased \\
Serum globulin & $3.4 \mathrm{~g} / \mathrm{dL}$ & $2-3.5 \mathrm{~g} / \mathrm{dL}$ & Normal \\
Serum calcium & $8.6 \mathrm{mg} / \mathrm{dL}$ & $9-10.5 \mathrm{~g} / \mathrm{dL}$ & Decreased \\
\hline
\end{tabular}

TLC total leukocyte count, TPC total platelet count, INR (PT) international normalized ratio (prothrombin time), AST aspartate transaminase, ALT alanine transaminase, ALP alkaline phosphatase, GGT gamma glutamyl transpeptidase

some degree of fibrosis, occasional nodules, and a few feathery hepatocytes without any inflammation (Fig. 3).

Our patient was finally diagnosed as having the syndromic form of paucity of bile ducts (AGS) because, along with bile duct paucity, he had cholestatic jaundice and the typical ophthalmic and facial appearance. $\mathrm{He}$ was treated with ursodeoxycholic acid, vitamin $\mathrm{D}_{3}$, calcium, vitamin A solution, and multivitamins. His parents were advised to attend regular follow-up appointments but did not attend. Our patient died 1 year after the final diagnosis because of massive blood vomiting.

\section{Discussion}

AGS (arteriohepatic dysplasia) is a rare disease with an incidence of 1 in 100,000 live births [6]. Over 500 cases of AGS have been reported since its initial description $[1,7]$. AGS is diagnosed if three or more of the following five major features are present: cardiac murmur, posterior embryotoxon, butterfly-like vertebrae, renal abnormalities, and characteristic facies, along with histological diagnosis of bile duct paucity [8]. The exact prevalence of this syndrome in the Indian subcontinent is not known; only five cases have been reported so far [5, 9-13]. This is an autosomal dominant syndrome, with the gene (JAG1) being traced to chromosome 20 [13]. Mild to moderate mental retardation may be present. Patients commonly present before 6 months of age with either neonatal jaundice or cardiac

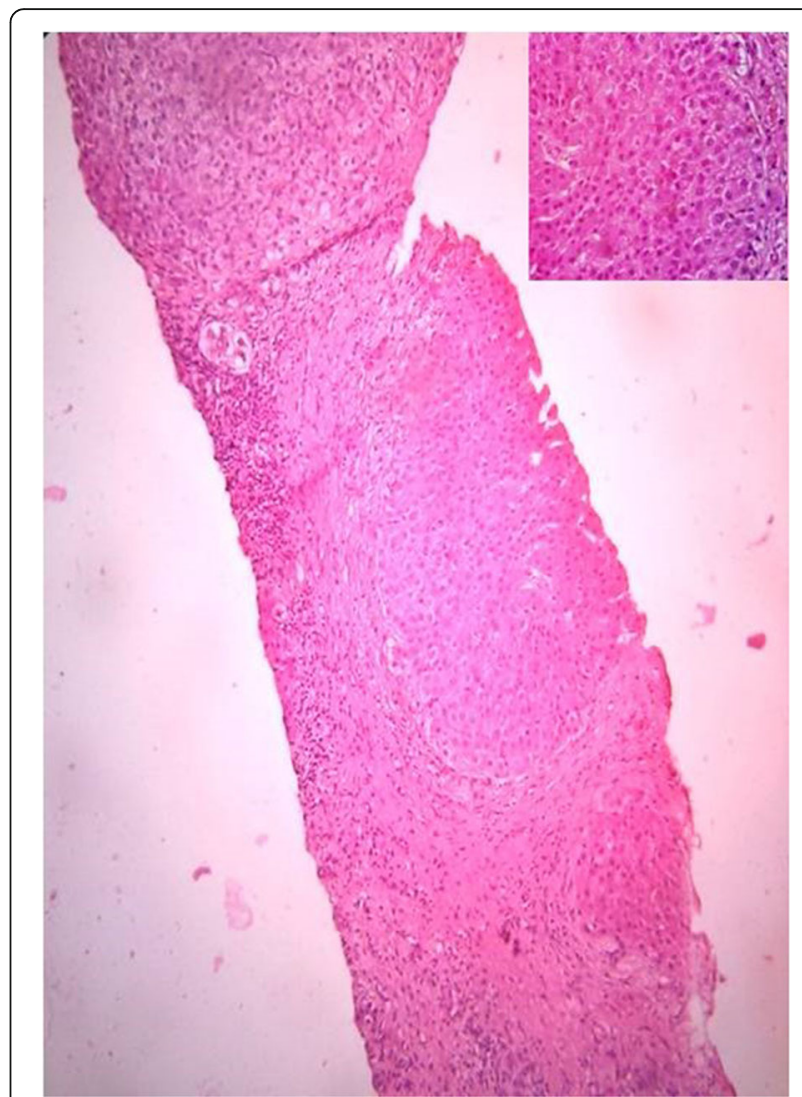

Fig. 3 Liver histology findings of the patient

murmurs; later they may present with poor linear growth, a broad forehead, pointed chin, deep-set eyes, and elongated nose with a bulbous tip. Hepatic disease is the predominant disease in AGS.

Our case had three out of the five major features of the syndrome with no vertebral or renal defects. He had cholestatic jaundice, typical facial features consistent with AGS, posterior embryotoxon, iris strands in the eye, and bile duct paucity demonstrated by histologic study. A "partial" or "incomplete" form of AGS was previously reported from India by Shendge et al. [11]. Our patient had an intermittent productive cough associated with rhinorrhea, soreness of throat, and sneezing mostly in the rainy seasons and winter months, which suggests the possibility of decreased immunity and recurrent viral infections.

The differential diagnoses of our case included progressive familial intrahepatic cholestasis (PFIC), childhood primary sclerosing cholangitis (PSC), congenital hepatic fibrosis, childhood autoimmune hepatitis, childhood primary biliary cirrhosis, alpha-1-antitrypsin deficiency, and cystic fibrosis.

PFIC is a clinical syndrome of intrahepatic cholestasis which presents in infancy or early childhood, and usually progresses rapidly to fibrosis and end-stage liver disease, whose confirmatory diagnosis can be made only 
following genetic analysis [14, 15]. Patients with PFIC can present with deafness, pancreatic insufficiency, cholelithiasis, and diarrhea, and it usually runs in families, which was not so in our case, ruling out the possibility of PFIC. Patients with PSC usually present with recurrent cholangitis and diarrhea because most patients usually have inflammatory bowel disease, especially ulcerative colitis $[14,15]$. Our patient did not have such a presentation. Congenital hepatic fibrosis can present with upper gastrointestinal hemorrhage or recurrent cholangitis and can be associated with medullary sponge kidneys; these features were not present in our case. Diagnoses of childhood autoimmune hepatitis and childhood primary biliary cirrhosis can be confirmed based on typical liver histology findings and the presence of typical autoantibodies [14], which were absent in our case. Patients with alpha-1-antitrypsin deficiency can present with panacinar emphysema and can be diagnosed by typical liver histology finding such as the presence of periodic acid Schiff-positive diastase-resistant globules in the periportal hepatocytes, which were absent in our case. Patients with cystic fibrosis can present with meconium ileus, micro-gall bladder, and respiratory abnormalities; these features were absent in our case.

Having excluded these possibilities, our patient was finally diagnosed with AGS, most importantly because his symptoms fulfilled three out of the five criteria along with bile duct paucity in the liver histology, which is necessary for diagnosis of AGS. Our case was different from other previously published studies because of a history suggestive of fat-soluble vitamin deficiencies, such as a recurrent history of fracture in his upper limbs, night blindness, and recurrent epistaxis; he also had café au lait spots and very early onset of liver cirrhosis compared to previously published reports on AGS. Our case was quite different from other published case reports and we believe it may be the first case report on AGS in which the patient has café au lait spots as a skin manifestation.

Previous case reports of AGS with prominent skin manifestations have described the presence of well-defined, painless, indurated papules and plaques on the skin over the metacarpophalangeal and interphalangeal joints of the hands, eyelids, and the axillary, antecubital, inguinal, and popliteal folds of both sides, along with the presence of cutaneous xanthoma or tendinous xanthoma [9].

The long-term prognosis of AGS is uncertain, with congenital heart disease, hepatic cirrhosis, intracranial bleeding, and renal abnormalities being the commonest factors affecting mortality. Though a biliary diversion procedure can be undertaken to treat this disease, liver transplantation is the surgical treatment of choice. The estimated 20-year survival rates are $80 \%$ for those not requiring liver transplant and $60 \%$ for those requiring it
[16]. Thus AGS is a rare and grave systemic disorder that should be part of the differential diagnosis of every case of prolonged neonatal jaundice and warrants aggressive treatment to minimize poor outcome.

\section{Limitations}

Our case had certain limitations; we were not able to carry out the necessary genetic or chromosomal analysis for confirmation of the diagnosis of AGS. We were unable to carry out any genetic tests in our center because of the limited availability of sophisticated diagnostic facilities to diagnose any type of genetic disorder in our resource-constrained setting. Although our patient had an intermittent productive cough for 6 years, we were unable to perform sputum culture, a polymerase chain reaction test for virus infection, or screening to test for tuberculosis. We were also unable to perform assays of all the fat-soluble vitamins and other coagulation parameters except for total platelet count and international normalized ratio (prothrombin time) because of the limited diagnostic facilities in our resource-constrained setting.

\section{Conclusions}

This particular syndromic form of paucity of bile duct disorder has been rarely reported in Indian literature so far. This is probably the first case report on AGS manifesting with café au lait syndrome and such an early onset of chronic liver disease, and therefore worth reporting. Because these patients usually have multisystem involvement, they may be evaluated by multiple clinical subspecialties and therefore it is necessary that all clinicians should be aware of this grave and rare disease, and they should take adequate measures for timely referral to the appropriate higher specialties so that a poor outcome can be prevented by early aggressive management.

\section{Acknowledgements \\ We thank Dr Amrita Mohanty, postgraduate student of the Ophthalmology Department in SCB Medical College, for her help with the ophthalmological examination and interpretation of the findings, and Dr Prasanjit Mohanty, Professor and Head of Department of Dermatology at the SCB Medical College, for his help in the dermatological evaluation. We also thank Dr Jyotiranjan Champatiray, Associate Professor of the Pediatric Department at the SCB Medical College, for helping with the clinical evaluation of our patient. We would like to gratefully acknowledge our thanks to the patient and his parents for their cooperation.}

\section{Funding}

This study was not sponsored by any funding agency.

\section{Availability of data and materials}

Not applicable as this is case report.

\section{Authors' contributions}

GKP evaluated the case, collected the pertinent history from the patient's attendants, obtained the written informed consent from the patient's attendants for publication purpose, collected the images, and drafted the 
manuscript; AS performed the liver biopsy after obtaining written informed consent from the patient's attendants because the patient was a minor; PN analyzed the case report and did necessary modifications; JN collected the images of the patient; PK Padhi and PK Parida analyzed the case report and did necessary modifications; KP did the histological analysis and designed the histological images; CP analyzed the case report and did necessary modifications; SPS analyzed the case report, and designed and modified the manuscript. All authors read and approved the final manuscript.

\section{Competing interests}

The authors declare that they have no competing interests.

\section{Consent for publication}

Written informed consent was obtained from the patient's legal guardians for publication of this case report and any accompanying images. A copy of the written consent is available for review by the Editor-in-Chief of this journal.

\section{Ethics approval and consent to participate}

Not applicable.

\section{Author details}

${ }^{1}$ Department of Gastroenterology, S.C.B. Medical College, Cuttack, Odisha, India. ${ }^{2}$ Department of Gastroenterology, IMS and Sum Hospital, Bhubaneswar, Odisha, India. ${ }^{3}$ Department of Pathology, S.C.B. Medica College, Cuttack, Odisha, India.

Received: 18 May 2016 Accepted: 27 October 2016

Published online: 30 November 2016

\section{References}

1. Alagille D, Odievre M, Gautier M, Dommergues JP. Hepatic ductular hypoplasia with characteristic facies, vertebral malformations, retarded physical, mental and sexual development and cardiac murmur. J Pediatr. 1975;86:63-71

2. Alagille D, Estrada A, Hadchouel M, Gautier M, Odievre M, Dommergues JP. Syndromic paucity of interlobular bile ducts. J Pediatr. 1987;110:195-200.

3. Wang JS, Wang XH, Zhu QR, Wang ZL, Hu XQ, Zheng S. Clinical and pathological characteristics of Alagille syndrome in Chinese children. World J Pediatr. 2008:4:283-8.

4. Spinner NB, Colliton RP, Crosnier C, Krantz ID, Hadchouel M, Meunier-Rotival M. Jagged 1 mutations in Alagille syndrome. Hum Mutat. 2001;17:18-33.

5. Bhatia V, Kumar P. Alagille syndrome with a previously undescribed mutation. Indian Pediatr. 2014:51:314-6.

6. Scheimann A. Alagille syndrome. http://reference.medscape.com/article/ 926678overview. Accessed 13 Aug 2004

7. Watson GH, Miller V. Arteriohepatic dysplasia: familial pulmonary arterial stenosis with neonatal liver disease. Arch Dis Child. 1973:48:459-66.

8. Kamath BM, Spinner NB, Piccoli DA. Alagille syndrome. In: Suchy F, Sokol RJ, Balistreri WF, editors. Liver disease in children. 3rd ed. New York: Cambridge University Press; 2007. p. 326-45.

9. Sengupta S, Das JK, Gangopadhyay A. Alagille syndrome with prominent skin manifestations. Indian J Dermatol Venereol Leprol. 2005;71:119-21.

10. Nigale V, Trasi SS, Khopkar US, Wadhwa SL, Nadkarni NJ. Alagille syndrome. A case report. Acta Derm Venereol. 1990;70:521-3.

11. Shendge H, Tullu MS, Shenoy A, Chaturvedi R, Kamat JR, Khare M, et al. Alagille syndrome. Indian J Pediatr. 2002;69:825-7.

12. Hadchouel M. Alagille syndrome. Indian J Pediatr. 2002;69:815-8.

13. Oda T, Elkahloun AG, Pike BL, Okajima K, Krantz ID, Genin A, et al. Mutations in the human Jagged 1 gene are responsible for Alagille syndrome. Nat Genet. 1997:16:235-42.

14. Nakanishi Y, Saxena R. Pathophysiology and diseases of the proximal pathways of the biliary system. Arch Pathol Lab Med. 2015;139(7):858-66.

15. Wong KC. How to apply clinical cases and medical literature in the framework of a modified "failure mode and effects analysis" as a clinical reasoning tool-an illustration using the human biliary system. J Med Case Rep. 2016;10(1):1

16. Emerick KM, Rand EB, Goldmuntz E, Krantz ID, Spinner NB, Piccoli DA. Features of Alagille syndrome in 92 patients: fand relation to prognosis. Hepatology. 1999:29:822-9.

\section{Submit your next manuscript to BioMed Central and we will help you at every step:}

- We accept pre-submission inquiries

- Our selector tool helps you to find the most relevant journal

- We provide round the clock customer support

- Convenient online submission

- Thorough peer review

- Inclusion in PubMed and all major indexing services

- Maximum visibility for your research

Submit your manuscript at www.biomedcentral.com/submit 